\title{
Explorando a Tangibilidade como Estímulo ao Desenvolvimento do Pensamento Computacional
}

\author{
Cristina Paludo Santos, Renan Daniel Volz, Denilson Rodrigues da Silva \\ Universidade Regional Integrada do Alto Uruguai e das Missões (URI) \\ 98.802-470 - Santo Ângelo - RS - Brasil \\ paludo@san.uri.br, renandvolz@san.uri.br, deniro@san.uri.br
}

\begin{abstract}
This paper presents the development of a tangible interaction artifact whose application was directed to the development of computational thinking, through introductory concepts of programming logic. The objective is to contribute with the area of Informatics in Education, establishing a link between tangibility and concrete materials in order to integrate the educational benefits provided by both approaches for the conception of tangible learning objects.
\end{abstract}

Resumo. Este artigo apresenta o desenvolvimento de um artefato de interação tangível cuja a aplicação alvo foi direcionada ao desenvolvimento do pensamento computacional, por meio de conceitos introdutórios de lógica da programação. $O$ objetivo consiste em contribuir com a área de Informática na Educação, estabelecendo um elo entre tangibilidade e materiais concretos de forma a integrar os benefícios educacionais providos por ambas abordagens para a concepção de objetos de aprendizagem tangíveis.

\section{Introdução}

As discussões referentes às competências e aos processos de aprendizagem necessários para as pessoas que vivem, se educam e atuam no novo século, têm aproximado entidades profissionais, educadores e governos para o desenvolvimento de metodologias e ferramentas para a promoção do pensamento computacional em ambientes formais e informais de aprendizagem. Um traço comum às diferentes iniciativas é o uso de recursos tecnológicos para o desenvolvimento das habilidades relacionadas ao pensamento computacional, seja por meio de linguagens de programação visual direcionadas para crianças, de jogos ou por meio de kits robóticos (Costa, 2016).

Este trabalho insere-se no elenco de tais iniciativas, contudo busca ampliar as experiências de aprendizado por meio de objetos de aprendizagem tangíveis. Esta abordagem consiste em embutir elementos computacionais em objetos físicos, criando um novo grupo de recurso didático que une as vantagens da manipulação física às formas inovadoras de interação provida pela computação.

Estudos indicam que as interfaces tangíveis são capazes de promover um engajamento mais forte e de longa duração com um maior potencial para envolver as crianças e para promover a aprendizagem (Carbajal e Baranauskas, 2016). Falcão (2007) enfatiza que as interfaces tangíveis ao enriquecer os materiais concretos, podem ajudar a estimular e trabalhar diversos sentidos, promover uma maior inclusão de portadores de 
VIII Congresso Brasileiro de Informática na Educação (CBIE 2019)

Anais do XXV Workshop de Informática na Escola (WIE 2019)

deficiências, estender e ampliar o número e tipos de experiências de aprendizagem e contemplar a exploração através de interação, imaginação, criatividade e colaboração.

No que se refere ao impacto dos manipulativos na aprendizagem Piaget (1972) proveu uma fundamentação epistemológica em que teorizou que as crianças podem frequentemente resolver problemas quanto têm à disposição materiais concretos antes de conseguir resolvê-los simbolicamente. Assim, as experiências com objetos do ambiente físico são básicas no desenvolvimento das estruturas cognitivas.

Dentre as vantagens que manipulativos trazem para a aprendizagem e que estão alinhados aos propósitos do processo de desenvolvimento do pensamento computacional citam-se: (a) permitir que as crianças demonstrem conhecimento nas suas ações físicas mesmo sem saber falar sobre esse conhecimento; (b) permitir que as crianças resolvam problemas que elas ainda não conseguem resolver simbolicamente e, (c) facilitar a abstração de relações simbólicas a partir de várias instâncias concretas.

Neste sentido, busca-se, por meio desta proposta, estabelecer um elo entre tangibilidade e materiais concretos de forma a integrar os benefícios educacionais providos por ambas abordagens para a concepção de objetos de aprendizagem tangíveis, tendo como foco educacional escolhido para ser trabalhado por esta interface o pensamento computacional.

Embora existam vários trabalhos já realizados ou ainda em andamento que propõem interfaces tangíveis para a Educação, este campo ainda está repleto de oportunidades e desafios. O diferencial introduzido nesta pesquisa é que, além da aplicação de cunho educacional, também foi desenvolvido um artefato tecnológico baseado na arquitetura tabletop que pode ser utilizado por diversas e diferentes aplicações.

Uma descrição mais detalhada das dimensões tecnopedagógicas da aplicação e artefato propostos é apresentada nas próximas seções, organizadas da seguinte forma: a Seção 2 apresenta alguns trabalhos relacionados que serviram de suporte para as decisões de projeto. A Seção 3 apresenta as principais características do artefato de interação tangível concebido. A Seção 4 apresenta as características da aplicação para ser utilizada no artefato. A Seção 5 apresenta uma visão geral dos testes realizados e o processo de validação junto ao público-alvo da aplicação. Por fim, a Seção 6 apresenta as considerações finais.

\section{Interfaces Tangíveis na Educação}

A literatura contempla alguns trabalhos relacionados a essa temática, dentre os quais destacam-se as propostas de Gutiérres (2015), Braga e Baranauskas (2015) e Carbajal e Baranauskas (2016).

Gutiérrez (2015) apresenta um modelo para a criação de ambientes computacionais para a criação de narrativas. Buscou potencializar a atividade de contar histórias com o uso de tecnologias tangíveis visto que, contar histórias é considerado uma atividade que desenvolve a criatividade, a imaginação, a manipulação de conceitos abstratos e, em alguns casos, o desenvolvimento do pensamento lógico. Segundo o autor "a experimentação do ambiente de computação tangível, com professores e crianças durante dois semestres mostrou resultados positivos em termos de aceitação". 
VIII Congresso Brasileiro de Informática na Educação (CBIE 2019)

Anais do XXV Workshop de Informática na Escola (WIE 2019)

Já Braga e Baranauskas (2015) propuseram a criação de um jogo, denominado Magiblocks, desenvolvido para utilizar o tablet como plataforma para interação com objetos de aprendizado tangível. O público alvo são crianças autistas e busca ensina-las a reconhecerem formas geométricas. Segundo os autores, tendo em vista as especificidades do público-alvo, é fundamental que as mesmas estejam em um ambiente familiar, já que, elas não lidam bem com mudanças repentinas de rotina. Por isso, a utilização do tablet como interface tangível é vantajosa para o contexto em questão. Contudo, o uso de um hardware pronto pode limitar a estrutura das aplicações desenvolvidas e crianças que tenham familiaridade com o dispositivo podem utiliza-lo de maneira indevida.

Por fim, o trabalho de Carbajal e Baranauskas (2016) aproximam-se do contexto considerado neste trabalho visto que busca introduzir conceitos de computação e pensamento computacional no processo educativo de crianças por meio de um ambiente de programação tangível. Através do uso em um cenário educacional real o ambiente de programação foi considerado de fácil aprendizado. Também demonstraram que os conceitos básicos de programação foram compreendidos. $\mathrm{O}$ ambiente criado separa a interface de entrada da interface de saída, assim, não é propriamente uma mesa multitoque. Tornar o ambiente uma mesa multitoque poderia torna-la mais interativa.

Apesar das propostas apresentarem o uso de interfaces tangíveis, elas distinguem-se da presente proposta nos seguintes aspectos: o artefato tecnológico criado por Gutiérrez (2015) foi construído para ter apenas um tipo de aplicação, a construção de narrativas de histórias, o que torna o artefato tecnológico limitado e o diferencia da presente proposta, em que o artefato poderá conter diferentes aplicações; os trabalhos de Braga e Baranauskas (2015) e Carbajal e Baranauskas (2016) apresentam aplicações com contexto e público-alvo distintos, que podem ser utilizadas como base para o desenvolvimento de aplicações para serem executadas no artefato proposto neste trabalho.

\section{Artefato Baseado na Arquitetura Tabletop}

$\mathrm{O}$ artefato computacional com suporte à interação tangível é baseado na arquitetura tabletop (mesa multitoque) e caracterizado pela personificação completa concentrando interações com objetos posicionados em sua superfície, modificando seu ambiente virtual em função das entradas fornecidas pelo mesmo.

Dentre as principais tecnologias de software utilizadas para a criação do artefato destaca-se neste trabalho o TUIO (TUIO, 2018). O TUIO é um protocolo de domínio público e Interface de Programação de Aplicação (API) própria para desenvolvimento de superfícies multitoque tangível. Este protocolo permite a transmissão de uma descrição abstrata do estado atual da superfície interativa, incluindo interações provenientes de estados dos objetos tangíveis.

O TUIO codifica os dados de controle de um aplicativo de rastreamento, que são obtidos por meio de uma câmera de vídeo e o envia para um aplicativo cliente capaz de decodificar o protocolo e desencadear certas ações que são projetadas na superfície. A estrutura do protocolo permite que as aplicações desenvolvidas sejam distribuídas, onde um computador pode ser responsável pelo processo de detecção das interações e outro pelo processamento e atualização do cenário da aplicação. 
VIII Congresso Brasileiro de Informática na Educação (CBIE 2019)

Anais do XXV Workshop de Informática na Escola (WIE 2019)

A detecção de objetos tangíveis quando utilizado a arquitetura TUIO é realizada por uma aplicação de monitoramento denominada TUIO Tracker Application. A aplicação mais adequada é o reacTIVision que consiste em um framework de visão computacional, de plataforma aberta e multiplataforma, utilizado para o rastreamento de marcadores fiduciais fixados em objetos físicos. O reacTIVision é uma aplicação independente, que transmite mensagens TUIO via porta UDP 3333 para qualquer aplicativo cliente habilitado. O protocolo TUIO foi inicialmente projetado para codificar o estado de objetos tangíveis a partir de uma superfície de tela interativa.

Para detectar os objetos físicos presentes sobre a mesa, o reacTIVision faz a identificação através de marcadores fiduciais que deverão estar afixados na parte inferior do manipulável. Os marcadores fiduciais são códigos visuais identificados pelo software e convertidos em um numeral que identificará a função do objeto físico. Existem 216 marcadores fiduciais implementados (utilizando os códigos entre 0 e 215) para a detecção pelo reacTIVision. Essa quantidade de marcadores é significativa e improvável de ser extrapolada, já que, como eles identificarão objetos reais é necessária uma quantidade maior que 216 funções para a aplicação realizar, pois, vários objetos com a mesma função podem ser identificados com o mesmo marcador. Porém, se alguma aplicação necessitar de uma quantidade maior que a implementada nos marcadores fiduciais, o desenvolvedor poderá criar um novo tipo de marcador.

Quanto ao hardware utilizado para a concepção do artefato utilizou-se: uma webcam Maxprint 60294-1 com resolução de captação de 480k como o sensor de rastreamento das interações com a superfície da mesa; um projetor de LED Acer C120 com as dimensões de $13 \times 8 \times 3 \mathrm{~cm}$ com uma capacidade de projeção bastante semelhante com projetores de dimensões padrões que é utilizado para exibir a interface gráfica da aplicação que estiver sendo executada na interface tangível, ou seja, será responsável por exibir as ações que foram desencadeadas pelas interações do usuário. O projetor é utilizado no modo "Espelho", em que a imagem é exibida de maneira refletida para o usuário e a resolução escolhida é de 1280x768 pixels; um espelho com as dimensões de $24 \times 29 \mathrm{~cm}$ utilizado para aumentar o tamanho da projeção realizada no vidro da mesa multitoque, a projeção da imagem é de cerca de $80 \times 45 \mathrm{~cm}$; um computador desktop Dell Inspiron 530, 2 GB de memória RAM, processador Intel Pentium Dual CPU E2200 2.20 GHz, com o sistema operacional Windows XP Professional, versão 5.1, de 32 bits que roda as aplicações de rastreamento e a aplicação cliente.

Quanto às dimensões do artefato, o mesmo foi projetado segundo a NBR 9050 para a definição da altura, largura e profundidade definida em $90 \times 90 X 60 \mathrm{~cm}$. Essa altura se encaixa na faixa ideal para que seja feito o mínimo esforço para pessoas em pé e sentada e, também, permite que a interação de crianças seja facilitada. Já, as dimensões quanto à largura e profundidade foram determinadas para privilegiar os aspectos de usabilidade e de acoplamento de todos os componentes de hardware dentro da estrutura.

No que se refere ao posicionamento dos dispositivos no artefato destacam-se as seguintes características: (a) o projetor foi fixado a 1,6 centímetros na parede frontal da mesa multitoque e a 54,5 centímetros do vidro que fica na parte superior. A lâmpada do projetor está apontada para a parte inferior do artefato, projetando na direção do espelho. Este posicionamento do projetor faz com que o espelho seja posicionado junto a parede da frente e na parte inferior do artefato. A webcam também está posicionada na parte 
VIII Congresso Brasileiro de Informática na Educação (CBIE 2019)

Anais do XXV Workshop de Informática na Escola (WIE 2019)

inferior do artefato e a 32 centímetros da parte da frente. O computador fica localizado na parte traseira. A Figura 1 apresenta o posicionamento dos componentes numa vista frontal do artefato (a) e com uma visão superior (b).

(a)

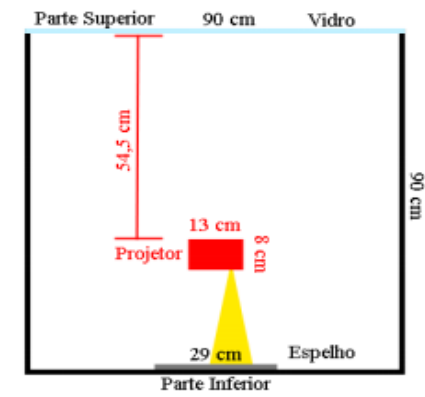

(b)

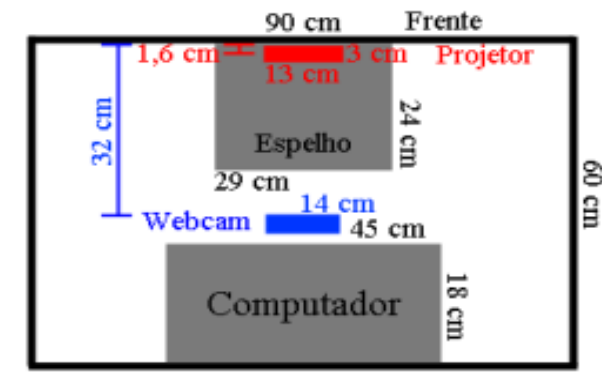

Figura 1. Posicionamento dos componentes físicos do artefato

Cabe destacar que a definição das dimensões do artefato impacta nos aspectos computacionais das aplicações clientes que serão executadas nele. Assim, durante o desenvolvimento da aplicação deverá ser levado em consideração a superfície de interação adequada com as dimensões propostas.

\section{Aplicação "Robô no Labirinto"}

Os resultados provenientes dos estudos realizados e baseados em outras experiências de uso de jogos voltados à iniciação a lógica de programação como forma de estimular o desenvolvimento do pensamento computacional originaram um protótipo da aplicação denominada "Robô no Labirinto". A aplicação foi desenvolvida no NetBeans IDE 7.3, a versão do Java utilizada foi a 1.6.0_41. A aplicação de rastreamento utilizada foi a reacTIVision na versão 1.5.1 para sistemas operacionais x32.

A Figura 2 apresenta a estrutura de comunicação entre as partes que integram o artefato tangível concebido. Essa estrutura de comunicação tem como parte inicial o reacTIVision, que é responsável por detectar alterações nos objetos físicos (como inserção ou remoção) ou alteração no posicionamento. De acordo com as alterações detectadas, a aplicação de rastreamento realiza um processamento, escolhe o tipo de mensagem TUIO adequado e realiza a codificação da mensagem usando o formato do protocolo OSC, para enviar para a aplicação cliente. Todo esse processo já está implementado na aplicação.

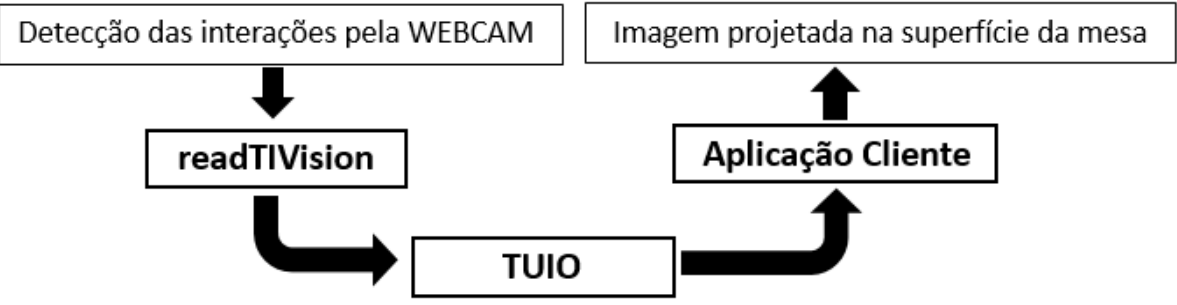

Figura 2. Estrutura de comunicação entre as aplicações

Criada a mensagem (que será de um dos quatro tipos especificados), ela é enviada por meio do protocolo TUIO para a aplicação cliente. Na aplicação cliente, onde há uma instância da classe TuioClient, é realizada a leitura para obter as 
VIII Congresso Brasileiro de Informática na Educação (CBIE 2019)

Anais do XXV Workshop de Informática na Escola (WIE 2019)

mensagens. Detectado uma mensagem é feito a descompactação e o seu processamento para a execução das funções adequadas.

O público-alvo para a aplicação são crianças já alfabetizadas ou em um processo avançado de alfabetização (6 e 9 anos), pois, é necessário ter um conhecimento básico de leitura para obter as informações através das telas de ajuda e de controles. Segundo Piaget (1972), as crianças dessa faixa etária estão no estágio de desenvolvimento cognitivo chamado operatório concreto, em que inicia o desenvolvimento de operações mentais. O repertório comportamental inclui pensamento espacial; noção de causa e efeito; classificação e seriação; raciocínio indutivo; noção de conservação e habilidade para lidar com números, solucionando problemas matemáticos envolvendo as quatro operações. Conhecer estas especificidades é de suma importância para que se possa estruturar ações que contemplem complexidade conceitual de acordo com o estágio de desenvolvimento cognitivo dos usuários.

A aplicação caracteriza-se como um jogo, denominado "Robô no Labirinto", em que o usuário deve conduzir o robô até a saída de um labirinto. Para a realização da movimentação do robô o usuário deve encadear os objetos físicos para realizar as tarefas propostas e, assim, de maneira intuitiva e lúdica começar a desenvolver o pensamento computacional, visto que, essa sequência de objetos físicos criados pode ser percebida como um algoritmo em que os objetos são funções e variáveis.

A primeira sequência de objetos deve conduzir do ponto inicial até o ponto 01 . Posteriormente deve ser criado a sequência de objetos para movimentar o robô do ponto 01 até o ponto 02 e, por fim, do ponto 02 até a saída. Em caso de erro na sequência, o robô retornará até o ponto anterior que estava posicionado. O labirinto é formado por seis quadrados no eixo $\mathrm{X}$ e cinco quadrados no eixo $\mathrm{Y}$.

O usuário realizará toda a interação com a aplicação desenvolvida através dos objetos físicos detectados pelo sistema. $\mathrm{Na}$ interface inicial da aplicação são apresentadas as instruções das possíveis tomadas de decisão que o usuário pode tomar, o labirinto e informações básicas de uso da interface, caso o usuário necessite de ajuda para a efetuar a interação. Também há interfaces que explicam ao usuário o funcionamento dos objetos físicos de controle do jogo. Quando o Robô sai do labirinto, o usuário recebe a informação do número de movimentos que executou para alcançar o objetivo, bem como o tempo gasto. A Figura 3 apresenta as principais interfaces da aplicação.

Para concepção do jogo buscou-se contemplar as seguintes heurísticas de jogabilidade (Barcelos et al., 2011): (a) Os controles devem ser claros; suas respectivas ações de resposta devem ser imediatas; (b) O jogo deve possibilitar que o jogador desenvolva habilidades que serão necessárias futuramente; (c) O jogador deve encontrar um tutorial claro de treinamento e familiarização com o jogo; (d) Todas as representações visuais devem ser de fácil compreensão pelo jogador; (e) O layout e os menus devem ser intuitivos e organizados de forma que o jogador possa manter o seu foco na partida; (f) $\mathrm{O}$ layout e os menus devem ser intuitivos e organizados de forma que o jogador possa manter o seu foco na partida; ( $\mathrm{g}$ ) $\mathrm{O}$ cenário deve ser envolvente criando um laço com o jogador e seu universo; (h) $\mathrm{O}$ objetivo principal do jogo deve ser apresentado ao jogador desde o início e, (i) O jogo deve fornecer dicas, mas não muitas. 
VIII Congresso Brasileiro de Informática na Educação (CBIE 2019)

Anais do XXV Workshop de Informática na Escola (WIE 2019)

Além disso, dentre as diferentes formas de se trabalhar os jogos na educação básica, este trabalho adota como estratégia a individuação, visto que a experiência individual não corre os riscos de efeitos colaterais da experiência competitiva, em que há o fato de que nem todos os jogadores se empolgam, e muitas vezes preferem evitar confrontos e se sentem mais confortáveis com situações individuais onde não ocorrem perdedores, nem o risco de desequilíbrio de esforço entre os jogadores que pode ocorrer em jogos cooperativos (Galdino et al., 2015).
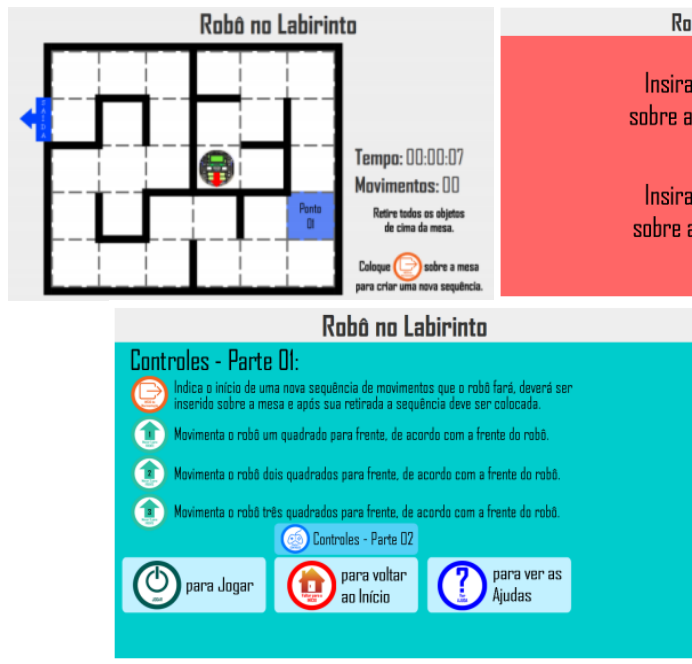

Rabo no Labirinto

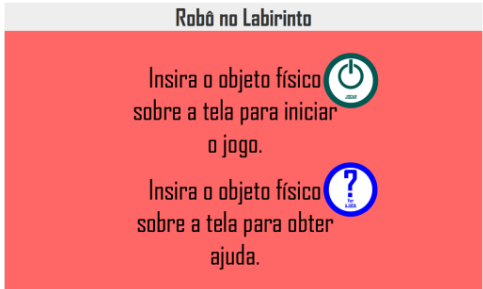

Parabéns!

Você criou uma sequência de movimentos que conduziu o robô até a saída do Labirinto.

Voce saiu do labirinto em 34 movimentos

प tempo gasto para sair do labirinto foi de 00:03:13 para Jogar (10) ${ }_{\text {ao Início }}^{\text {para }}$

Figura 3. Interfaces do jogo "Robô no labirinto"

A aplicação detecta quatorze tipos diferentes de objetos físicos, divididos em duas categorias: objetos de transição de tela e objetos de controle de jogo, conforme apresentado na Figura 4.
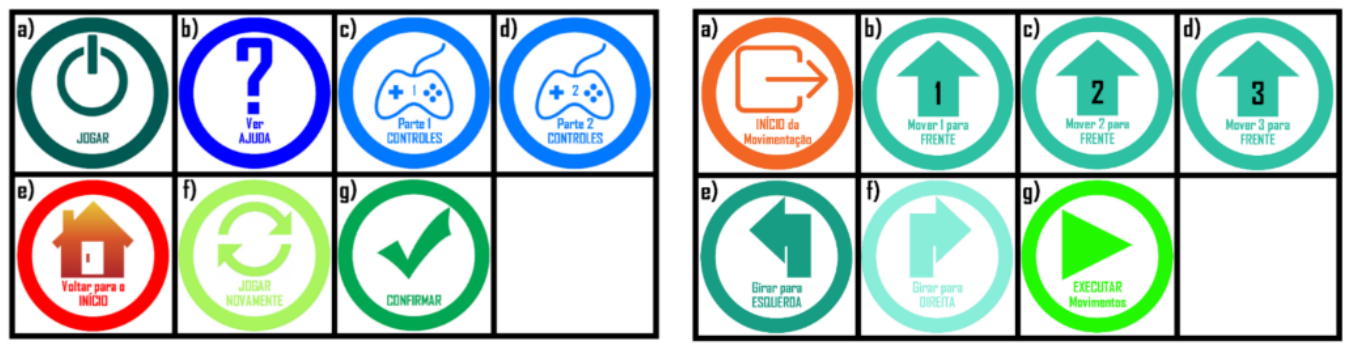

Figura 4. Objetos físicos para interação com a aplicação

Os objetos de transição servem para acessar as funcionalidades do jogo, enquanto os objetos de controle servem para o usuário definir a estratégia de movimentação do robô no labirinto.

\section{Cenários de testes e validação com o usuário}

Para a verificação das funcionalidades do artefato tecnológico criado foram realizados vários testes envolvendo a utilização da aplicação cliente desenvolvida. Os testes realizados foram principalmente voltados a detecção de falhas e bugs na aplicação e possíveis problemas para detecção de múltiplos objetos físicos. Além de verificar detalhes relacionados à usabilidade. Para fazer essas verificações foram realizados múltiplos testes buscando executar várias possibilidades que o usuário poderia gerar. Para orientar a condução dos testes foram criados 23 cenários. 
VIII Congresso Brasileiro de Informática na Educação (CBIE 2019)

Anais do XXV Workshop de Informática na Escola (WIE 2019)

Durante o desenvolvimento dos testes, o reacTIVision apresentou alguns problemas para detectar alguns objetos físicos quando inseridos vários objetos ao mesmo tempo. Esses problemas para a detecção de objetos ocorreram pela baixa luminosidade na parte interna da estrutura física do artefato e também pelo material utilizado na superfície (vidro transparente). Para a falha ser resolvida foi necessário inserir uma fonte de iluminação auxiliar e utilizar um papel sulfite amarelo para possibilitar que a webcam detectasse os objetos. Após a realização dos ajustes todos os testes foram realizados com êxito. A Figura 5 apresenta a aplicação sendo executada na mesa durante a realização dos testes. A sequência de objetos físicos para criar o movimento que o robô deverá executar para chegar até o ponto 02 é mostrada na parte inferior da parte da superfície de interação reconhecida pela webcam. Os outros objetos reconhecidos pela aplicação estão dispostos em volta da mesa, na parte não captada pela webcam. Não foi encontrada nenhuma falha na aplicação durante os testes.

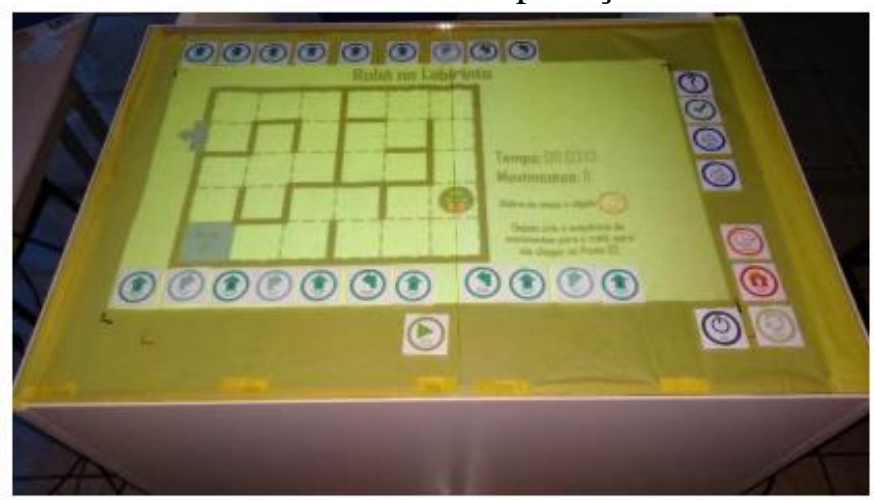

Figura 5. Aplicação sendo executada no artefato durante a realização dos testes

Uma vez realizados os ajustes necessários para garantir o efetivo funcionamento do artefato e da aplicação, os mesmos foram disponibilizados para uma turma de 25 crianças na faixa etária de 8 a 9 anos. Não houve registro fotográfico do uso do artefato a fim de preservar a imagem das crianças participantes. Para viabilizar a avaliação, uma equipe de 3 colaboradores monitorou a aplicação das atividades.

Destaca-se que o processo avaliativo foca na reação das crianças ao experimentarem a interação tangível com vistas a verificar se esta é motivadora; proporciona uma boa experiência de uso; e gera uma percepção de utilidade educacional. Os dados foram analisados qualitativamente, através da descrição dos fatos ocorridos durante os experimentos e a interpretação dos pesquisadores sobre eles.

Inicialmente, o jogo foi disponibilizado para as crianças sem que houvesse qualquer interferência por parte dos avaliadores. Com isso, pretendeu-se verificar se a interface é intuitiva o suficiente permitindo que os usuários percebam qual o objetivo da aplicação desde o início da interação e compreendam a forma de interação a ser empregada. Tais quesitos foram considerados plenamente satisfatórios, pois não houveram dúvidas por parte das crianças sobre o objetivo a ser alcançado e como interagir com o jogo.

Dentre a descrição dos fatos encontrou-se várias vezes os termos entusiasmo, diversão, excitação, alegria e/ou facilidade quando caracterizam a interação das crianças durante a atividade com o sistema tangível. Também foram registrados os seguintes comentários: "Tem que botar os comandos tudo de uma vez só?"; "Deixa eu pegar um 
VIII Congresso Brasileiro de Informática na Educação (CBIE 2019)

Anais do XXV Workshop de Informática na Escola (WIE 2019)

papel para montar uma estratégia"; "Posso fazer de novo?"; "Esse jogo é muito fácil"; "Que legal!", o que indica o engajamento das crianças durante a atividade proposta.

Identificou-se confusões das crianças em relação aos sentidos esquerda e direita. No entanto, os signos atribuídos aos comandos que indicam as setas direcionais do girar acabaram sendo aprendidos pelas crianças que faziam a ligação entre a seta escolhida e a movimentação do robô. Um aspecto interessante é que apesar dos comandos envolverem implicitamente conceitos de lógica de programação e pensamento computacional que permitem a movimentação do robô no labirinto, isto não se tornou um objetivo explícito na interação. Para as crianças tratava-se apenas de um jogo que prende sua atenção e as encoraja a vencer o desafio.

Acredita-se que o caráter experimentalista da proposta ganhou destaque visto que se apresentou como uma novidade tanto para as crianças quanto para a professora. $O$ fato das interfaces tangíveis não serem utilizadas no ambiente escolar onde ocorreram as atividades contribuiu para o entusiasmo de todos. Inclusive a professora nos relatou que alunos de outras turmas estavam ávidos por utilizar o artefato. $\mathrm{O}$ experimento foi disponibilizado por um período adicional de duas semanas na escola para que demais alunos interessados pudessem utiliza-lo, atendendo ao pedido da direção da escola.

\section{Considerações Finais}

Observa-se que diante de uma cultura digital torna-se inevitável o impacto da tecnologia na área educacional. $\mathrm{O}$ uso das ferramentas computacionais, de forma lúdica propicia flexibilidade e criatividade, encorajando o pensamento criativo, ampliando o universo, saciando a curiosidade, alimentando a imaginação e estimulando a intuição, e tudo isso contribui para o aprendizado.

Com vistas a trilhar caminhos em prol da ampliação de espaços de aprendizagem, a pesquisa descrita neste artigo apresentou o desenvolvimento de um artefato de interação tangível cuja a aplicação alvo foi direcionada ao desenvolvimento do pensamento computacional, por meio de conceitos introdutórios de lógica da programação. A avaliação realizada baseia-se na perspectiva de representantes do público-alvo, à luz da interpretação de especialistas em tecnologia educacional e interação humano-computador. As análises geradas abarcam aspectos de interação humano-computador, experiência do usuário e compreensão conceitual, tais como: motivação, complexidade conceitual, compreensão dos elementos da interface, lógica de execução e formas de interação.

Os resultados demonstram que o desafio, a interface e a forma de interação contempladas no protótipo fazem dele um recurso educacional atraente e envolvente, capaz de motivar as crianças. Além disso, conduzem a novos direcionamentos em relação a ampliação de seus aspectos interacionais e conceituais. Um ponto importante a ser mencionado é que o artefato desenvolvido pode ser utilizado por qualquer tipo de aplicação em que a interação tangível seja pertinente, desde que atendidos os requisitos de integração entre as tecnologias empregadas.

Cabe ainda destacar que os resultados obtidos impulsionaram o uso do artefato nas disciplinas "Interação Humano-Computador", "Laboratório de Programação" e “Tópicos Especiais em Computação", ofertadas durante o primeiro semestre de 2019, 
VIII Congresso Brasileiro de Informática na Educação (CBIE 2019)

Anais do XXV Workshop de Informática na Escola (WIE 2019)

possibilitando novos estudos, outras iniciativas de desenvolvimento e utilização de estratégias educacionais que possibilitem o estímulo e a expressão das habilidades criativas, explorando as potencialidades da tecnologia produzida para ampliar as experiências de aprendizagem também aos alunos do ensino superior.

Particularmente na disciplina de Tópicos Especiais em Computação está sendo utilizado o método TangiSAM que consiste em "um conjunto de artefatos tangíveis construído para a realização de avaliações de estados afetivos" (Moreira, 2019), buscando tornar a atividade de avaliação do artefato mais lúdica e ao mesmo tempo facilitar a percepção dos elementos de representação dos estados afetivos, uma vez que o público-alvo é composto principalmente por crianças, ampliando assim o escopo da avaliação para além da ergonomia e usablidade.

\section{Referências Bibliográficas}

Braga, Kim Pontes; Baranauskas, Maria Cecília Calani. "Desafios e Possibilidades da Interação Tangível Móvel no Contexto da Educação de Crianças Autistas". Tecnologias, Sociedade e Conhecimento, Campinas, vol. 3, n. 1, dez. 2015.

Carbajal, Marleny Luque; Baranauskas, M. Cecília C. "Evolução de um ambiente para programação tangível e avaliação de seu uso em cenário educacional". In: Anais do Congreso Internacional de Informática Educativa, Santiago, 2016.

Costa, Sarita Bastos. Desenho de interface para o desenvolvimento do pensamento computacional no Ensino Básico. 2016. Tese de Doutorado.

Barcelos, Thiago Schumacher et al. Análise comparativa de heurísticas para avaliação de jogos digitais. In: Proceedings of the 10th Brazilian Symposium on Human Factors in Computing Systems. Brazilian Computer Society, 2011.

Falcão, Taciana Pontual; Gomes, Alex Sandro. Interfaces tangíveis para a educação. In: Brazilian Symposium on Computers in Education (Simpósio Brasileiro de Informática na Educação-SBIE). 2007. p. 579-589.

Galdino, C.; Silva, S. R. N; Costa, E. B. Planejando um serious game para a prática de Programação. In: Proceeding of IV Congresso Brasileiro de Informática na Educação - CBIE 2015. Maceió, Sociedade Brasileira de Computação: 2015.

Gutiérrez Posada, Julián Esteban. "Interfaces Tangíveis e o Design de Ambientes Educacionais para Co-construção de Narrativas". 2015. 253 p. Tese de Doutorado em Ciência da Computação. Instituto de Computação, Universidade Estadual de Campinas, Campinas, 2015.

Moreira, Eliana Alves; Dos Reis, Julio Cesar; Baranauskas, M. Cecília C. Artefatos Tangíveis e a Avaliação de Estados Afetivos por Crianças. Revista Brasileira de Informática na Educação, v. 27, n. 1, 2019.

Piaget, Jean. A Vida e o Pensamento do Ponto de Vista da Psicologia Experimental e da Epistemologia Genética. In: Piaget. Rio de Janeiro: Forense Universitária, 1972.

Tuio. "Specification Software Developer Contributors". Disponível em: $<$ hhpts://tuio.org/>. Último acesso: outubro, 2018. 